\title{
E-Commerce Pricing Opportunities: And How to Exploit Them
}

\author{
S. Balamurugan, M. Selvalakshmi
}

\begin{abstract}
In today's competitive era of E-commerce, companies are struggling to provide a satisfactory price level to meet customer's demands. One of the most important metric to meet customer's expectations is the price which will ultimately clinch the deal. The present study is to discuss about the different price strategies and its impact on e-marketing. By understanding these pricing strategies, more efficient marketing strategies will be available, that will drive internet and e-commerce. A detailed analysis is done on the pricing strategies and its difference for effective implementation in e-commerce. The e-retailers should try to offer discounts and to reduce customers search cost for more business than brick and mortar store.
\end{abstract}

Keywords: E-commerce, Pricing strategy, Smart pricing, cost.

\section{INTRODUCTION}

The marketing landscape is changing in India rapidly. The Consumers are evolving and their mind sets are shifting. The basic components of the showcasing blend are named as the estimating choices. There is no total least cost, yet the cost must compare to the client's apparent estimation of the item. The goal of estimating is to charge what an item is worth to the client and to take care all things considered.. The market prices are set based on three basic factors. The first is product cost, which is based on minimum price only and a few firms can afford to do as per their capacities. The subsequent factor is the focused costs for equivalent items. That makes a value roof or upper limit. The other one is an ideal value that is between the lower and upper limits for each item. The interest capacity of the item is controlled by the eagerness and capacity of clients to purchase. Most of the e-commerce retailers have realized the importance of pricing and adjusting their prices. Retail giants - Amazon changes its prices every ten minutes on average.

More than $60 \%$ online shoppers world wide consider ecommerce pricing as the very first criteria for buying decision, and $70 \%$ of online shoppers believe that they would get a better deal in the online shopping than in brick \& mortar stores. Another important finding is that 53\% of shoppers will purchase products left in shopping carts. It happens when those products are offered at lower prices. To manage the pricing function in e-commerce, executives and managers must know the factors affecting pricing decisions and have a framework for approaching pricing issues.

Revised Manuscript Received on September 25, 2019

S.Balamurugan, Academic Counsellor, Indira Gandhi National Open University, and Business Administration, Research Scholar, Madurai Kamaraj University, Madurai, India. E-mail : balaseeni.65@gmail.com

Dr.M.Selvalakshmi, Professor, Thiagarajar School of Management, Madurai, India. E-mail : selvalakshmi@tsm.ac.in

\section{LITERATURE REVIEW:}

The marvel of B-to-C online business has spread quickly and internationally in the course of the most recent few years. It is constantly developing at uncommon rate (Nilashi et al, 2016). The organizations and buyers are at their focal points in light of the B-to-C internet business. The organizations create computerized customer facing facades for the arrangement of merchandise and ventures. It is conceivable with time productivity and mechanical enhancements. The buyers do shopping on the web on account of high paces of comfort, cash and time investment funds. (Mousavizadeh et at 2016). Phan and Poon (2000) analyzed the web shopping among web and non-web purchasers. They found that cost and quality impact the purchaser decision between a retail location and web shopping center. Kim and Lim (2001) proposed that the buyers consider the data quality as a significant factor, and it prompts the likelihood of procurement through the web. Today the Consumers need more width and profundity of cutting-edge data and they see web as exchange situated medium instead of an amusement based medium (Ran dall, 1997). Liao and Cheung (2001) examined about the shopper traits towards web based e-shopping. They discovered numerous elements influence e shopping. They are the existence substance of items, exchanges security, value, seller quality, IT instruction. The web use and their experience are altogether influencing the underlying readiness of individuals to e-shop on the web.

Gummeras et al (2004) mentioned that a prompt response to customer's requests can increase perceived convenience. It will diminish uncertainty to large extent.

Gounares et al., (2005) investigated about the specific antecedents of perceived service quality in the internet environment. They are trust, understanding, energy and degree of utilizing web based business, recurrence of buys. Kukar-Kinney and Close (2010) proposed an augmentation of inhibitors to the online purchase process. The inhibitors are social impacts, absence of accessibility, high value, customer's monetary status, time, security. While comparing various online service quality scales Kalia (2017) observed that security, price, website design, and privacy, responsiveness, ease of use, customer service and personalization are the consistently cited dimensions. 


\section{E-Commerce pricing opportunities: And how to exploit them}

\section{KINDS OF PRICING}

3.1 Cost-based pricing strategy

It is basic and first step, to find out the cost of the product. It is to make the product, and calculate exactly is a little tricky. It does not only contain the unit purchasing price of the goods from a supplier and includes all the over head expenses. The overhead expenses are associated with the internal e-commerce operation of the company.

\subsection{Consumer oriented pricing strategy}

This strategy aims about the prices according to the perceived or estimated value of the product or service to the customer. Here the unique selling proposition (USP) and the nature of the customers to the vendors are measured. The customers are familiar with the prices and market conditions. Now the manufactures cannot control the price. The character of certain business people is to reduce the size of the product, when the cost of manufacturing increases.

\subsection{Psychological pricing strategies}

Numerous purchasers utilize the cost as a marker of value. In any case, the brain research of the costs is likewise considered. The astounding items are offered at high cost, for instance, profoundly valued TVs which convey glory costs are sought after. The costs are set at odd sum, for example, $\$ 19.95$ rather than $\$ 20$ : \$399.90 rather than $\$ 400$. These odd costs, by brain science may bring more deals.

\subsection{Competitive pricing strategies}

It is a pricing strategy based on the market conditions and competitions.

\section{a) Penetration pricing :}

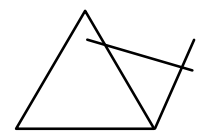

Cost of production (or) the Amount paid to Vendors or Suppliers
$+$

Overhead Costs

-Administration

-Marketing

-Logistic

-Inventory etc.
The online business organizations lean toward this sort of valuing and a low cost is planned in the underlying stage so as to catch more prominent piece of the overall industry. On the off chance that the estimating strategy is to catch more noteworthy piece of the pie, at that point this is done distinctly by reception of low costs in the underlying stage. As a result of the low costs, the business volume increments and rivalry tumbles down.

\section{b) Dynamic Pricing:}

In dynamic pricing, competitor pricing is frequently updated and this information can be used as a triggering factor to update the prices. This will help to get maximum profits from each customer.

\subsection{Discounts and Promotions}

After the cost is fixed, any online business organization may confront the issue to diminish the cited cost. The value differential is known as the distinction between the cost cited and the net cost charged. This cost is decreased is made as impetuses to purchasers to meet focused weight. The customers are urged to buy in mass. For instance $\$ 4$ for one pen $\$ 35$ for 10 pens and $\$ 60$ for 20 pens. This kind of amount markdown will be as free units.

During leeway season, the clients are permitted the occasional limits on buys. For example, the air coolers are commonly sold during summer seasons and to empower deals during winter season (off season), where no deals might be conceivable. The web based business organization can pursue this procedure. This diminishes stockpiling cost and empowers plant utility.

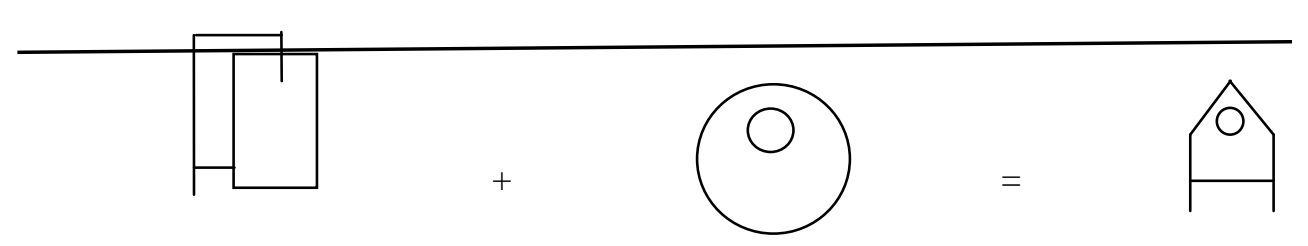

Total cost

\section{COMPETITIVE PRICING IN E COMMERCE}

As more company get in to business, the market grows, and first mover advantages are exhausted, the competition starts to build up. Business must now fight to gain an edge in the market, which contains well-connected and well-informed consumers. Due to the rapid penetration of comparison shopping websites, consumers can choose and find the best deals on the desired products they want with just a few clicks. So the solutions to this, e-commerce business track
Profit

Selling Price competitor prices automatically, instead of relying on resource-intensive manual operations.

1. Selecting which competitors to track.

2. Selecting which products to track

3. Price updates and stock availabilities

This is another strategy of price monitoring and that's spotting historical trends. This helps to analyze the competitors over all pricing strategies for certain brands or categories.

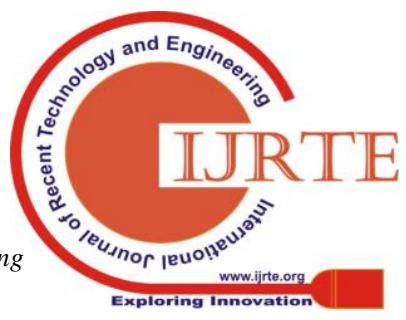


With the right strategy and right tool

a, One can easily see an overview of price trends

b, Product life cycle stage

c, Opportunities to launch promotions

d, Regular patterns that are repeated every year

\section{Smart pricing}

E-commerce companies always want to command the best prices for their products still make profit. Smart pricing helps them to stop undercutting their prices to achieve competitive advantage and allow them to set always optimal prices automatically. One way is reprising strategies by this one can be competitive while still increasing the profits by watching over all costs. By smart pricing strategy, they can sell as many products as possible. It works well for e-commerce business that have a large inventory of products they need to get rid of Smart pricing approach can fit very well in e commerce business to gain a sophisticated pricing strategy.

\section{CONCLUSION AND MANAGERIAL IMPLICATIONS:}

The cost of the item is a significant factor influencing the web based purchasing conduct. The costs of the web store ought not be higher than those of physical stores. There has been proof by specialists that the web customers don't like to purchase on the web if the costs are higher (vrechopoulos et al., 2001). The clients look for bottomless decision and low cost from internet shopping (Khan et al 2015). There must be decrease in conveyance cost and it will help the readiness of clients for web based shopping. (liao and cheung., 2001)

E-retailers may offer limits and buyer lean toward value advancements over consistently. The low cost is offered in light of the fact that it gives them more noteworthy feeling of financial control and increase. The retailers should attempt to decrease clients search costs by fusing search system and give rundown costs, sell off costs or advancement over recent months (Helander and Khalid, 2000). Next the retailers can send update email with limited time special to client. That is offering lower or free delivering on the things or data with respect to value decrease on the things (Close and Kinney, 2010). Sometimes companies can offer slow service at lower or no cost to any location to tap price sensitive buyers (Keeney 1999). It is recommended that online marketers should provide richer product details and descriptions (Jurvenpaa and Todd 1997).If customer get adequate information they want and transact easily, they are less likely to make search effort for lower price alternative (Wolfinbarger and Gilly, 2001).

\section{REFERENCES:}

1. Benjamin R, Wiganot R. "Electronic Markets and Virtual Value Chains on the Information Superhighway”. Sloan Management Review, 36(2), PP 31-41.(1995 January)

2. Brown M, Pope, N, Voges, K. "Buying or browsing? An exploration of shopping orientations and online purchase intentions". European Journal of Marketing, 37 (10/11), PP 1666-1684.(2003)

3. Choi. S, Stahi D, Whinston A, "The Economics of Electronic Commerce" Indiana polis: Macmillan Technical publishing. (1997)

4. Freund C.L., Weinhold D. "The Effect of the Internet on International trade Journal of International Economics", 62(1). PP 171-189.(2004)

5. Mckey J., Marshall, P. "Strategic Management of E-business “.Brisbane, John Wiley \& Sons.(2004)
6. Totonchi J, Manshady K, "Relationship between Globalization and E-commerce. International Journal of e-education, e-business, e-management and e-learning", 2(1), 83.(2012)

7. Koo DM \& Ju SH , "International effects of atmospherics and perceptual curiosity on emotions and online shopping intentions, Computers in Human Behavior", 26 (2010), PP 377-388

8. Alam S.S. \& Yasin N.M , "An Investigation into the Antecedents of customer satisfactions of online shopping' Journal of Marketing Development and Competitiveness", 5(1), (2010)

9. A. Day. "A Model of Monitoring web site effectiveness". Internet Research: Electronic Net working applications and policy, Vol 7, No.2, (1997), PP 109-115.

10. S.E. Kim, T. Shaw and H. Schneider, "Website design bench marking within Industry groups, Internet Research", Vol.13, No.1 (2003), PP $17-26$

11. M.Y Kiang and R.T.Chi "A framework for analyzing the potential benefits of Internet Marketing", Journal of Electronic Commerce Research, Vol 2, No.4 (2001), PP 157-163.

12. R.R. Ruckman, http://www.imgrind.com/10-advantages of internet Marketing/ 10, Advantages of Internet Marketing, (2012) January 19.

13. T.S.H Teo, V.K.G Lim and R.Y.C. Lai., "Intrinsic and extrinsic motivation in internet usage" omega, Vol.27, (1999), PP 25-37.

14. T.S.H Tes, "Usage and effectiveness of online marketing tools among Business - to -Consumer", B2C, firm in Singapore," International Journal of Information Management, Vol.25 (2005) PP 203-213.

15. Cha.J "Internet as a unique shopping Channel to sell both real and virtual items: A comparison of factors affecting purchase intention" Journal of Electronic Commerce Research, (2011). 12 (2) 115-132

16. Chen. I.D., Gillenson M. L., and Sherrell, D.I. "Enticing online consumers: An extended technology acceptance perspective". Information and Management (2002) 39(8). 705-719

17. Heijden, H.Vander., Verhagen, T., and Creamers M. "Understanding online purchase intentions : Contributions from technology and trust perspectives" European Journal of Information Systems (2003) 12(1), 41-48.

18. Joines J.I., Scherer. C.W and Scheufele "Exploring Motivations for consumer web and their implications for e-commerce" Journal of Consumer Marketing (2003), 20(2): 90-108

19. Kim. S.Y and Lim, Y.J. "Consumers perceived importance of and satisfaction with internet shopping" Electronic Markets (2001). 11 (3): 148-154.

20. Kovimaki. T. "Consumer satisfaction and purchasing behaviour in web-based shopping" (2001) Electronic Markets 11(3): 186-192.

21. Lohse. G. Bellman S., and Johnson E "Consumer buying behaviour on the Internet: Findings from panel data". Journal of Interactive Marketing (2000): 14(1) 15-29.

22. Phang C.W.S., Kankanhalli A., Ramakrishanan. K and Raman K.S. "Customers preference of online store visit strategies: An Investigation of demographic variables" European Journal of Information Systems (2010). 19 (3): 344-358

23. Rohm. A.J. and Swaminathan. V. "A typology of online shoppers based on shopping motivations" Journal of Business Research (2004). 57(7)., 748-757

\section{ABOUT THE AUTHOR}

S.Balamurugan graduated B.E from College of Engineering, Guindy, Chennai-25, Anna University and PGDM from Indian Institute of Management, IIMBangalore, MBA from Indira Gandhi National Open University, New Delhi, IGNOU, a old student from Indian Institute of Technology IIT-Khargpur, Submitted many technical papers in National and International Seminars. FIE from Institution of Engineers and FIV from Institution of Valuers. Ph.D Scholar in Madurai Kamaraj University, Madurai. 